\title{
A critical review of social sciences and humanities R\&D expenditure in South Africa, 2005-2014
}

AUTHORS:

Neo Molotja ${ }^{1}$ iD

Gerard Ralphs ${ }^{1}$ (iD

\section{AFFILIATION:}

${ }^{1}$ Centre for Science,

Technology and Innovation

Indicators, Human Sciences

Research Council, Cape Town,

South Africa

\section{CORRESPONDENCE TO: \\ Gerard Ralphs}

EMAIL:

gralphs@hsrc.ac.za

\section{DATES:}

Received: 30 Nov. 2017

Revised: 14 Feb. 2018

Accepted: 25 Feb. 2018

Published: 30 July 2018

\section{KEYWORDS:}

research; experimental

development; policy;

disciplines; funding

\section{HOW TO CITE:}

Molotja N, Ralphs G. A critical review of social sciences and humanities R\&D expenditure in South Africa, 2005-2014. S Afr J Sci. 2018;114(7/8), Art. \#2017-0407, 7 pages. http://dx.doi.org/10.17159/ sajs.2018/20170407

\section{ARTICLE INCLUDES: \\ $\times$ Supplementary material \\ $\times$ Data set}

\section{FUNDING:}

South African Department of Science and Technology

\section{(C) 2018. The Author(s).} Published under a Creative Commons Attribution Licence.
Expenditure on research and experimental development in the social sciences and humanities (SSH) in South Africa has almost doubled over the past decade. However, fine-grained analysis of patterns of R\&D expenditure in SSH research fields over the period 2005/2006-2014/2015 reveals a number of critical issues for both institutional planning and national policymaking. We demonstrate that most SSH R\&D expenditure in the 10-year reference period was targeted predominantly within just a few research fields: finance, economics, education, accounting and political science and public policy. By contrast, investment in SSH research fields such as architecture and habitat, media and communication studies, psychology, and transportation studies was strikingly low in the same period, with some research fields, such as dance or tourism, appearing to be at risk of decline. Using these R\&D data as a proxy, we argue, principally, that institutional $R \& D$ planners and national policymakers need to find a greater balance between current priorities and future needs, if SSH R\&D is to be 'leveraged' for larger socio-economic impacts, as is being envisaged in a new draft White Paper on Science, Technology and Innovation.

\section{Significance:}

- $\quad$ R\&D expenditure in the social sciences and humanities between 2005 and 2014 was concentrated in just a few research fields, such as finance, economics and education. By contrast, R\&D expenditure was comparatively low in research fields such as media and communication studies, technology management, architecture and habitat, and dance.

- In an era of rapid global technological change, but also deepening local societal challenges, South Africa's national and institutional policymakers face strategic R\&D choices. This article contributes to national debate about the status and perceived role(s) of the social sciences and humanities in this context.

\section{Introduction}

In countries across the income spectrum, investment in research and experimental development (R\&D) is predominantly targeted within the natural and health sciences, engineering, agriculture, and technology fields. By contrast, investment in the social sciences and humanities (SSH) is typically a small fraction of gross domestic expenditure on R\&D (GERD). This scenario is also true for South Africa: SSH expenditure as a percentage of total GERD reached about $20 \%$ in 2014 . However, our understanding of where specifically investment within the SSH is being targeted is limited. To redress this gap, we reviewed data from South Africa's annual R\&D Survey to critically investigate three key questions: What are the notable patterns of R\&D expenditure in the SSH over the period 2005-2014? Based on the evidence, what are the apparent drivers of R\&D performance in SSH related fields in this period? In what ways might future national and institutional policy be geared toward the mission of advancing and coordinating SSH R\&D in South Africa?

\section{Policy context}

The roots of the social sciences and humanities in South Africa can be traced through the colonial and apartheid periods, and are mirrored in the development and advancement of knowledge transfer and knowledge production through the first universities and government-funded research institutions..$^{1-4}$ After the democratic transition in 1994, the national policy framework on science and technology recognised that the SSH would have a significant place in post-apartheid society. In particular, the 1996 White Paper ${ }^{5}$ argued that:

\begin{abstract}
Human and social scientists play a vital role in providing critical analyses of national goals, choices about development policies and strategies, and other national issues pertaining to the transformation of South African society. Their involvement is crucial to a deeper understanding of social issues and to stimulating public debate that could lead to a reconsideration of chosen paths. Equally important to any society that seeks to be innovative in its response to the demands of global change is social research that identifies and explains global trends and their implications in political and economic life, communications and lifestyle changes. Research in the social sciences is therefore of fundamental importance, particularly at this point in our history. (p.12)
\end{abstract}

This passage is instructive because it contains three key normative assertions about how the SSH should be contributing to development in South Africa. They have a role as a source of critical analysis, deepening human understanding, and insight and explanation of social, political and economic phenomena. In a 2017 discussion document entitled 'Towards the 2017 White Paper on Science, Technology and Innovation: Inclusive development through science and innovation' ${ }^{\prime}$, there is an additional normative assertion about the SSH as extending beyond simply observation and commentary, to action: 'Purposeful inclusion of the SSH will be prioritised, not only in the role of observer and commentator, but also in the conceptualisation, planning, and execution of innovation initiatives' (p. 67; emphasis added). What this additional role points to is an active place for the SSH in a wider science, technology and innovation (STI) policy agenda; an agenda that is increasingly predicated on addressing 
the continued key societal and economic challenges faced by the country - namely, poverty, inequality, unemployment and weak growth - through the promotion of innovation for inclusive development. While the contextual realities South Africa faced in 1996 have perhaps become more complex in 2017, as a result of rapid technological change, both the 1996 and the present policy outlooks express strong support for the place and value of the SSH in the country.

At ground level, debate about the status of the SSH in South Africa came to a head in 2011, with scholars and commentators disputing whether the SSH had fallen into crisis or not. ${ }^{7-9}$ At around the same time, the National Institute for the Humanities and Social Sciences was established in 2013 through the Higher Education Act (Act No. 101 of 1997). ${ }^{10}$ Perhaps less well known in this context is that the UK Department for International Development and the Global Development Network commissioned two separate country studies concerning the social sciences in relation to the South African research environment ${ }^{11}$, on the one hand, and the political economy of the performance of social sciences research, on the other hand ${ }^{4,12}$.

What has emerged from this heightened attention on the status of the SSH in South Africa in recent years is a particularly useful, if partial, body of critical analysis of different sources of evidence that is helping to develop a more robust picture of SSH research performance. These sources of evidence include not only bibliometric ${ }^{11,12}$ and enrolment data $^{13}$, but also institutional profiling ${ }^{12}$, qualitative data from interviews with SSH scholars ${ }^{11}$, and political economy analysis ${ }^{4,7}$. In addition to this evidence and analysis, a critical review of R\&D expenditure patterns in the SSH in South Africa over a meaningful period of time can help to enrich our understanding of the challenges and opportunities for the SSH going forward, particularly insofar as the allocation of financial resources to particular research fields is concerned as well as the socio-economic objectives to which R\&D is directed. For institutional leaders, funders of R\&D, as well as for government policymakers, the assessment documented in this article is aimed at supporting strategic planning processes and research agenda setting, as well as at contributing to the debate about the role of SSH in South Africa.

\section{Methodology}

\section{Definitions}

There are numerous classifications of what constitutes research and experimental development (R\&D) within the social sciences and humanities. ${ }^{14}$ The definition of the social sciences and humanities used for this research was drawn from the terms of the research fields that are used in the collection of data in the South African National Survey on Research and Experimental Development (hereafter R\&D Survey). These research fields are given in Table 1.

$R \& D$ performance is defined in this article as R\&D performed within five sectors in the R\&D Survey: business, government, higher education, not-for-profit organisations, and science councils (Table 2). Within the R\&D Survey, performance reflects only input data, including nominal expenditure and personnel involved in R\&D. In this review, we do not cover data related to funding sources for R\&D in the SSH, as the R\&D Survey data on sources of funding is not disaggregated by research field.

According to the Frascati Manua/15, which was used in the collection of data referred to in this article:

$R \& D$ comprise creative work undertaken on a systematic basis in order to increase the stock of knowledge, including knowledge of man, culture and society, and the use of this stock of knowledge to devise new applications. (p.30)

The definition has since been updated by the OECD. ${ }^{16}$ Used interchangeably with $R \& D$ performance, $R \& D$ expenditure is defined, in this article, as current and capital expenditure reported by respondents in the R\&D Survey, covering the period 2005-2014.
Table 1: Social sciences and humanities research fields according to the South African R\&D Survey

\begin{tabular}{l|l}
\hline \hline \multicolumn{1}{c|}{ Social sciences } & \multicolumn{1}{c}{ Humanities } \\
\hline Accounting & Arts and culture \\
\hline Anthropology & Dances \\
\hline Archaeology and history & Historical and civilisation studies \\
\hline Architecture and habitat & Languages and literature \\
\hline Economics & Music \\
\hline Education & Other humanities not elsewhere \\
\hline classified
\end{tabular}

\section{Data sources}

Data for this paper were sourced from the Centre for Science, Technology and Innovation Indicators at the Human Sciences Research Council, which performs the South African R\&D Survey on behalf of the Department of Science and Technology (DST). Curated, aggregatelevel data are accessible to the general public on www.hsrc.ac.za. International comparative data were sourced from the UNESCO Institute for Statistics (www.uis. statdata.uis.unesco.org).

\section{Data anomaly}

In the R\&D Survey, respondents classify R\&D expenditure according to research field. If the research field is not listed in the code booklet, then respondents tend to report expenditure as 'Other social sciences not elsewhere classified' and 'Other humanities not elsewhere classified'. The impact is that when reviewing the data, there is often significant expenditure reported under these headings - in all sectors. This situation makes it impossible to unpack the expenditure in terms of the specific research field in which it has been invested. For this reason, definitive conclusions about the allocation of resources by research field cannot be drawn; however, it is possible to reflect on the overall quantum invested in the SSH.

Table 2 illustrates that the higher education sector has by far the largest amount of unclassified R\&D expenditure (when compared with other sectors). This difference is mostly explained by the diversity of research performed at higher education institutions, on the one hand, and the scope of the research field nomenclature on which the R\&D 
Survey rests, on the other hand. This issue is discussed further in our recommendations. In terms of the share of unclassified $R \& D$ expenditure to total R\&D expenditure in the SSH, all sectors, except the business sector, report between $11 \%$ and $19 \%$ unclassified R\&D expenditure - an issue which is also addressed in the recommendations section.

\section{Trend analysis}

\section{International trends}

When compared to expenditure on R\&D in the natural sciences and engineering over time, there has been an increase in the proportion of SSH R\&D expenditure in South Africa - from 12.3\% of GERD in 2005 (Figure 1) to $19.2 \%$ in 2014 (Figure 2). ${ }^{17}$ Argentina, South Africa and Malaysia reported the largest proportional increases in SSH R\&D in 2014 (as compared to 2005), while Chile, Turkey and Poland showed negative growth in SSH R\&D expenditure in 2014 as compared to 2005.
Compared to countries for which equivalent 2014 data were available for analysis, the ratio of GERD that is dedicated to SSH in South Africa is substantially higher than, for example, the Republic of Korea (3.6\%), Russian Federation (4.1\%), Malaysia (8.2\%), Poland (9.0\%), Chile $(9.8 \%)$, Turkey (15.3\%), Paraguay (16.2\%) and Uruguay (17.1\%). The only country to surpass South Africa in this regard in 2014 was Namibia, which dedicated $24.5 \%$ of GERD to SSH R\&D.

\section{National trends}

At the national level, the reported rand value of social sciences R\&D expenditure over the 10-year period was ZAR27.8 billion. Of a total of 19 social science research fields, 5 received $57.4 \%$ of this expenditure over the period 2005-2014 (Figure 3), with expenditure being highest in the finance research field. The next 4 research fields made up 18.1\% of the expenditure, with the remaining 10 research fields making up $12.4 \%$. Expenditure not classified by research field amounted to $12.1 \%$.

Table 2: $\quad$ R\&D expenditure in the social sciences and humanities research fields, by sector, including unclassified expenditure (2005-2014)

\begin{tabular}{|c|c|c|c|c|c|}
\hline Sector & $\begin{array}{l}\text { Total R\&D expenditure, } \\
\text { social sciences and } \\
\text { humanities (ZAR'000) }\end{array}$ & $\begin{array}{c}\text { Total unclassified } \\
\text { expenditure (ZAR'000) }\end{array}$ & $\begin{array}{c}\text { Proportion of } \\
\text { unclassified expenditure } \\
\text { (\%total) }\end{array}$ & $\begin{array}{c}\text { Unclassified } \\
\text { expenditure, social } \\
\text { sciences (ZAR'000) }\end{array}$ & $\begin{array}{l}\text { Unclassified expenditure, } \\
\text { humanities (ZAR'000) }\end{array}$ \\
\hline Business & 8580122 & 52178 & 0.61 & 50371 & 1808 \\
\hline Not-for-profit & 1455977 & 262777 & 18.05 & 224534 & 38243 \\
\hline Government & 3063845 & 349382 & 11.40 & 327398 & 21984 \\
\hline Science councils & 2075952 & 351523 & 16.93 & 174937 & 176586 \\
\hline Higher education & 17598571 & 3794335 & 21.56 & 2574087 & 1220248 \\
\hline Total & 32774466 & 4810196 & 14.68 & 3351328 & 1458868 \\
\hline
\end{tabular}

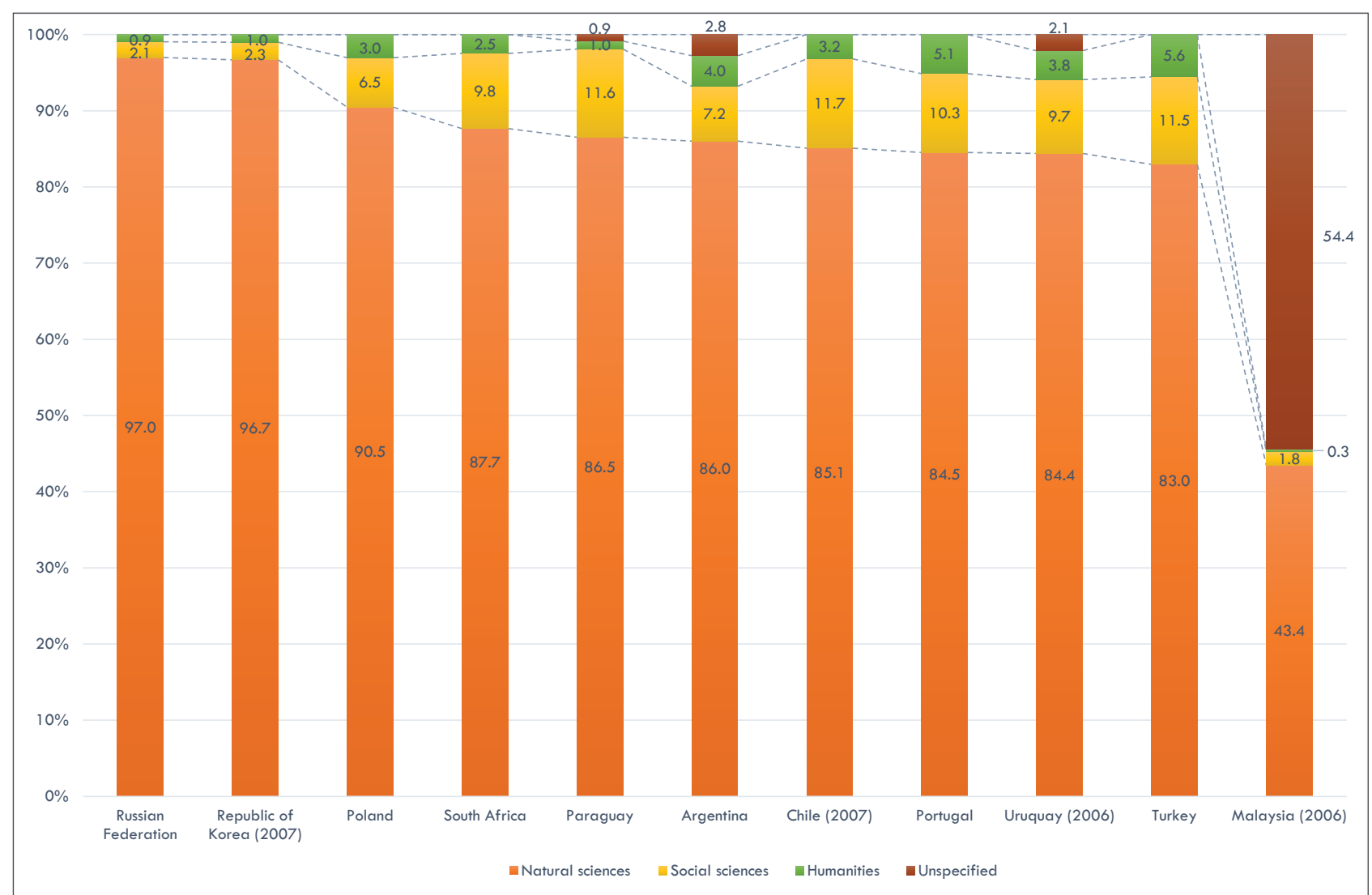

Data are for 2005 or the closest available year as indicated in brackets. The heading 'natural sciences' includes the following sub-categories: engineering and technology, natural sciences, medical and health sciences, and agricultural and veterinary sciences.

Figure 1: International comparison of R\&D expenditure by research field as a \% of GERD, 2005. 


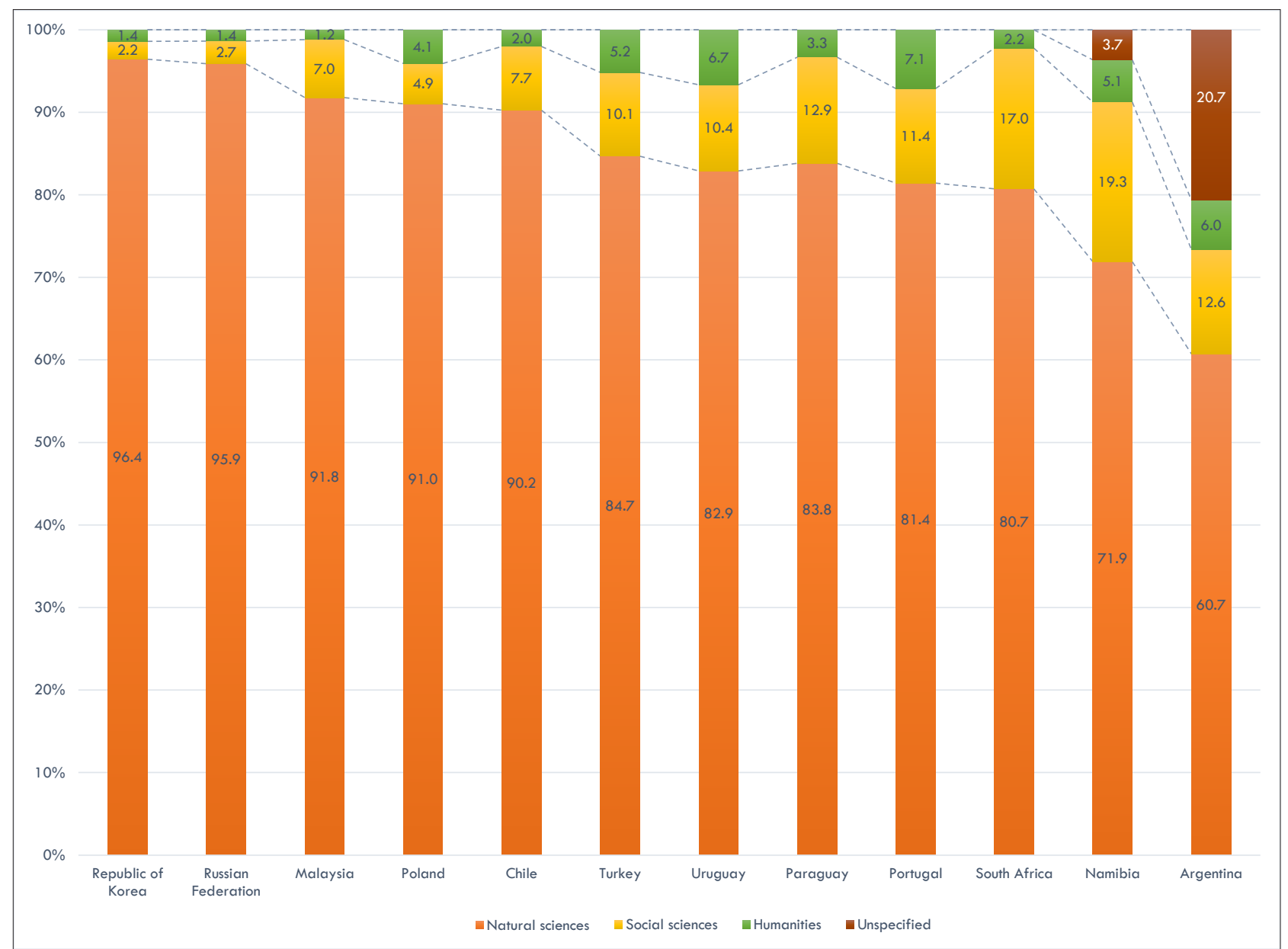

Data are for 2014 or the closest available year as indicated in brackets. The heading 'natural sciences' includes the following sub-categories: engineering and technology, natural sciences, medical and health sciences, and agricultural and veterinary sciences.

Figure 2: International comparison of R\&D expenditure by research field as a \% of GERD, 2014.

Social sciences R\&D expenditure more than doubled between 2005 and 2014, from ZAR1.4 billion to ZAR5.0 billion.

Nationally, the reported rand value of humanities R\&D expenditure over the 10-year period was ZAR5.0 billion. Excluding unclassified expenditure, five research fields of a total of seven made up $65.9 \%$ of the expenditure, with expenditure being highest in the languages and literature research field (Figure 4). Two research fields (philosophy, dances) made up the remaining $4.9 \%$ of expenditure. Expenditure not classified by research field amounted to $29.2 \%$. Humanities R\&D expenditure nearly doubled between 2005 and 2014, from ZAR350 million to ZAR657 million.

\section{Sectoral trends}

In the higher education sector, expenditure was registered in all of the SSH research fields specified in the R\&D Survey. Expenditure for R\&D in education (ZAR1.8 billion), law (ZAR1.7 billion), languages and literature (ZAR1.5 billion), management studies (ZAR1.3 billion) and economics (ZAR1.1 billion) was the highest over the 2005 to 2014 period. The next three research fields for which comparatively large amounts were spent were psychology (ZAR0.95 billion), accounting (R0.86 billion), and political sciences and public policy (ZAR0.80 billion). Research fields such as population studies (ZAR0.02 billon) and transportation studies (ZAR0.01 billion) only attracted a small amount of R\&D funding relative to the largest cohort. Finance-related R\&D grew very slowly off a low base over the 10-year period from 2005 to 2014.

In the science councils, the majority of SSH R\&D expenditure (69.3\%) was in a small number of research fields: political sciences and public policy (ZAR0.35 billion), education (ZAR0.35 billion), sociology (ZAR0.27 billion), population studies (ZAR0.24 billion), and economics (ZAR0.23 billion). Because of the low number of science councils that perform SSH R\&D, as defined by the R\&D Survey, this trend is not necessarily surprising.

In the government sector, SSH R\&D was performed across a wide range of research fields, with expenditure being highest in the economics (ZAR0.66 billion), political sciences and public policy (ZAR0.64 billion), management studies (ZAR0.36 billion), law (ZAR0.16 billion), and arts and culture (ZAR0.13 billion) research fields.

In the business sector, expenditure on R\&D was highest in the fields of finance (ZAR5.4 billion), accounting (ZAR1.8 billion), economics (ZAR0.59 billion), technology management (ZAR0.39 billion) and management studies (ZAR0.20 billion). Notably, in the finance research field, a sharp upward trend can be seen between 2011 and 2014. In the review of unit level data, it was noted that a single entity reported significant $R \& D$ expenditure in the finance research field in this period, which would explain the growth. Also notable is the increase in expenditure in the emerging issues research field, from ZAR0.952 million in 2013 to about ZAR17 million in 2014. There is only one humanities research field, languages and literature, which reflects expenditure between 2005 and 2010. It has to be emphasised that zero expenditure may be for other reasons, such as that the firms reporting on this expenditure might have ceased to be part of the survey or that no R\&D was undertaken in this field. 


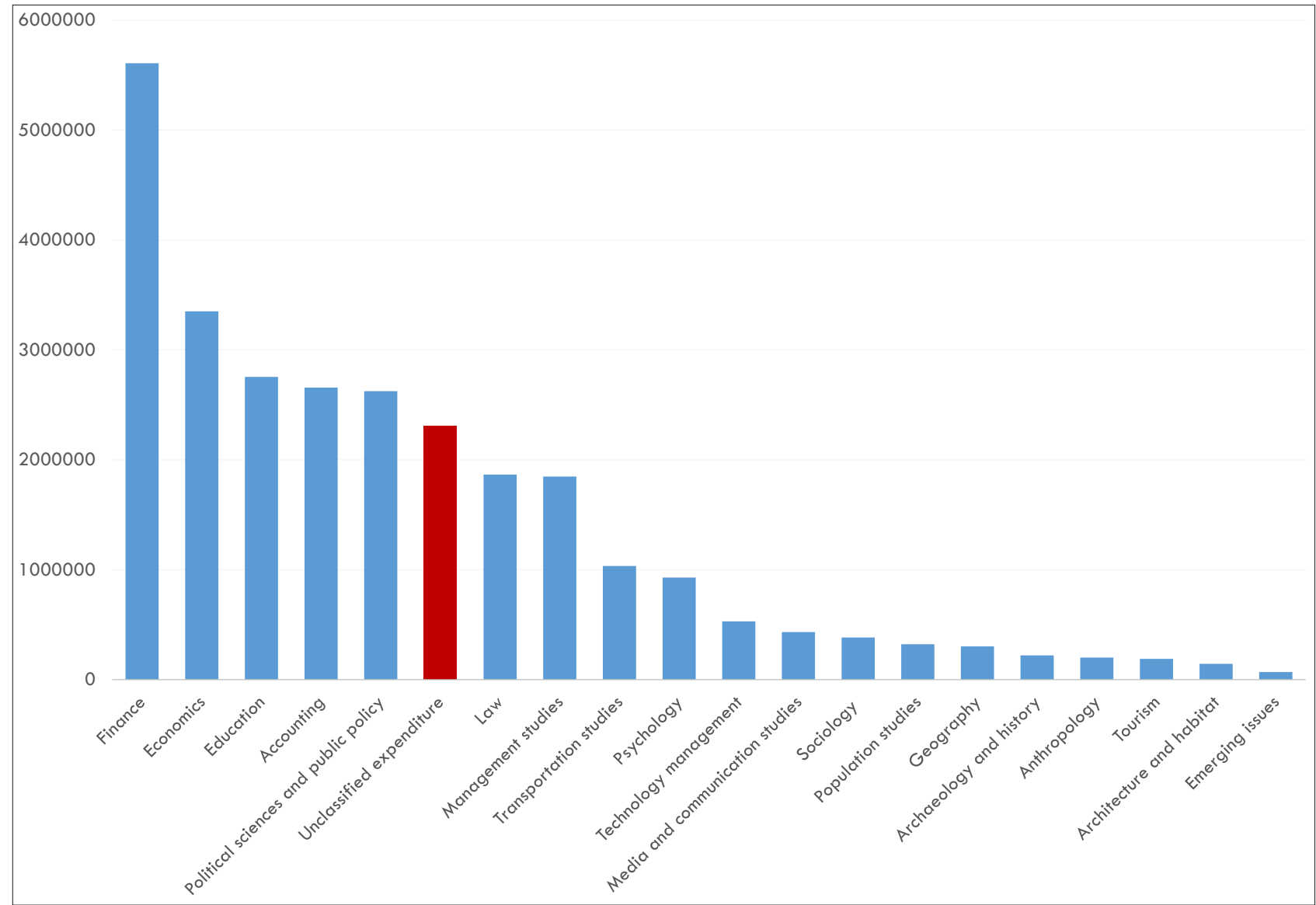

Figure 3: Total GERD by social sciences research field over 10-year period (ZAR'000)

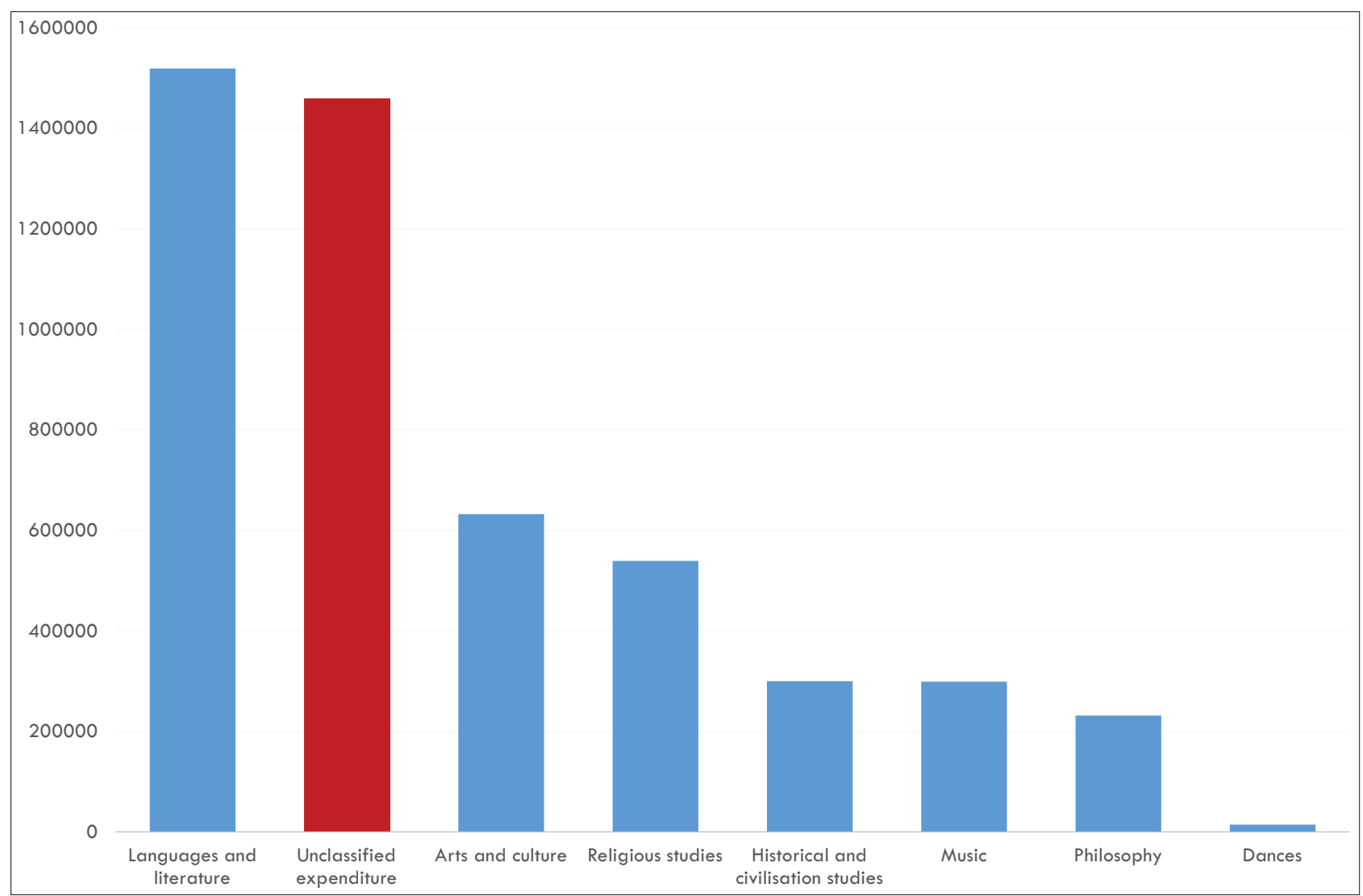

Figure 4: Total GERD by humanities research field over 10-year period (ZAR'000) 
In South Africa, R\&D expenditure by not-for-profit organisations (NPOs) is typically a small fraction of total GERD (in 2014, for example, it was $2.7 \%$; in 2005 it was $1.6 \%$ ), with the bulk of funding for NPO R\&D provided by foreign sources. Between 2006 and 2008, R\&D expenditure in the education research field registered a sharp decline (from ZAR0.06 billion to ZAR0.02 billion), while R\&D expenditure in the political sciences and public policy research field increased (from ZAR0.04 billion to ZAR0.06 billion). By 2014, however, the trend had reversed, with education R\&D expenditure (ZAR0.04 billon) surpassing that in the political sciences and public policy research field (ZAR0.03 billion). Interestingly, low as their expenditure is, NP0s tend to carry out research in most research fields. Emerging issues are also researched in the NPO sector, suggesting the extent to which the nomenclature of research fields included in the R\&D Survey does not capture fully the research areas in which NPOs are engaged.

\section{Key observations}

There are a series of key observations that can be drawn from these data in relation to the questions posed at the beginning of this article. The recommendations section of this paper elicits some of the implications of these observations for national and institutional planning and research agenda setting.

A first observation is that South Africa appears to invest proportionally more of its GERD in SSH than the countries for which equivalent data are available; and linked to this observation is that SSH research investment has virtually doubled over the period of a decade. At the macroscale, this observation could reinforce a view that, in fact, the SSH are not being overlooked in South Africa, but are rather being underpinned by increased investment driven by a recognition of the value of performing this type of R\&D. However, it would be premature to draw that conclusion - for all $\mathrm{SSH}$ research - without examining and analysing the expenditure across the different research fields and sub-fields comprising the $\mathrm{SSH}$, and the sectors in which the $R \& D$ is performed, because the playing fields may not be level across either. Indeed, when we performed the analysis of SSH R\&D expenditure data from 2005 to 2014 , as summarised in this article, what we uncovered was a picture that alarmed us as much as it served to reinforce the debate concerning the so-called 'crisis' moment for the SSH in South Africa. In particular, looked at from the perspective of research fields, the spend on SSH is very strongly geared to areas such as finance, economics, education, accounting and political science and public policy (Figures 3 and 4), in every year of the survey.

Commentators might perceive this situation to accurately reflect prevailing economic and social urgencies. However, the comparatively low spend in areas such as technology management and media and communication studies suggests that R\&D agenda setters and decisionmakers may not have paid sufficient attention to the opportunities and challenges posed by the exponential technological changes taking place globally under the heading of the Fourth Industrial Revolution.

Also concerning is the comparatively low spend in areas such as psychology, architecture and habitat, archaeology and history, sociology, and languages and literature. Given South Africa's complex colonial and apartheid legacies - which remain persistent and which traverse geo-spatial, subjective and linguistic experiences of citizens and communities, and which play out frequently in service delivery protests, contests over restitution, land and state-owned property, and, most recently, at our universities - there appears to be a weak alignment in research spend and these burgeoning societal trends. The same logic can be explored in the case of the relatively low levels of reported research investment in areas such as transportation studies, tourism and dance. To the extent that these areas arguably represent important potential economic and social development opportunities for South Africa, South Africans, and the globe more broadly, we would argue that SSH research decision-makers need to be alert to the apparent decline of these research areas, at worst, or the under-reporting of R\&D expenditures through the Survey, at best.

A further observation is that when the 2005-2014 spending on R\&D in the SSH is looked at from a sectoral perspective, the higher education sector spends by far the bulk on research in both humanities and the social sciences. As the key 'custodians' of the SSH disciplines, therefore, decision-makers from these institutions have an especially crucial role to play in advancing SSH research in South Africa and in redressing any imbalances that might be leading to decline in certain research fields. The other major players in SSH R\&D are business, government, science councils, and NPOs, in that order. Driven by their mandates, these institutions are arguably the main producers of applied SSH R\&D, addressed toward specific economic, advocacy or policy objectives (as opposed to basic research objectives), and their research agendas can be driven by the availability of research funds, whether local or international. Collectively, these institutions spend marginally more on social sciences R\&D than do higher education institutions, although of course comparatively less on humanities R\&D. The question this split raises for decision-makers from all sectors relates to the issue of impact, or perhaps more crudely put, value for money. The question is: are R\&D investments resulting in widespread impact, of the type South Africa desperately requires?

A caveat is in order at this point: what we know for sure is that a decade worth of R\&D spending in the SSH has not provided a miracle cure for persistent poverty, inequality, unemployment, and weak growth. But nor has the other $80 \%$ of South Africa's R\&D spend in the natural sciences, engineering and health research fields. However, to think that there is a linear relationship between R\&D and the solving of complex societal challenges is to misunderstand the many and, in some cases, competing drivers that underpin R\&D in different sectoral contexts, or within different research fields. Therefore, fine-grained analyses of research performance and research expenditure are required at both sectoral and research field level. Through this paper, we have tried to make a start on this agenda, although the need for further in-depth empirical work is acute.

Finally, from the perspective of the R\&D Survey instrument, what emerged clearly from the trend analysis presented above is the problem of unclassified R\&D expenditure in SSH. This unclassified $R \& D$ expenditure is a problem because it is impossible to analyse it at the level of research fields, not only for researchers and institutional planners, but also for funders of research (both private and public, local and international). This challenge presents a particular research design imperative for the managers of the R\&D Survey, to the extent that it would be desirable to reduce the reporting of unclassified R\&D expenditure as much as possible.

\section{Conclusions}

Since the dawn of democracy in South Africa, there has been intense debate about the role of the social sciences and humanities. On one level, this debate has been about the survival of individual research and teaching agendas, disciplines, and even entire institutions - essentially, a debate about funding. However, there is now a strong narrative in both institutional and national policy discourse, as reflected in the 1996 White Paper and its soon-to-be successor, that SSH research has a vital role to play in helping us to not only understand, but also address, the structural societal and economic challenges of our transition. The formation of the National Institute for Humanities and Social Sciences in 2013, and continued investment in R\&D through the National Research Foundation, the universities, the South African Research Chairs Initiative, and the Human Sciences Research Council, are reflections of the state's commitment in this regard.

At another level, there is possibly a tendency in our discourse to consider the SSH as an afterthought to the natural sciences and, as a result, to limit or shortchange SSH research. Whereas, what the data in this paper show is that the SSH in fact covers a multiplicity of research agendas, which are carried out under the umbrella(s) of different sectoral or organisational interests or mandates, which may be in direct competition or contradiction with each other, or, indeed, with the vision of the SSH in the White Paper. It is therefore unhelpful to characterise the SSH as a 'singular' entity in this way. Rather, what we need to better ascertain is the nature of the disciplinary funding economies of SSH R\&D, in order to assess whether inequities or skewed distribution of scarce resources (whether public, philanthropic or private) are hindering knowledge production in the public interest. 
For the R\&D Survey, as one of the instruments that can assist us to achieve this goal in the future, it will be essential to carefully review the nomenclature or taxonomy of research fields used to track R\&D expenditure and performance, and possibly even in the future, impact.

\section{Recommendations}

The three recommendations detailed below are directed at institutional planners, funders and the South African R\&D Survey managers, respectively.

For institutional planners: While the data show an alignment between R\&D and the major societal trends, what is also revealed is 'neglect' of potentially future strategic $R \& D$ opportunities. We recommend therefore that institutional planners consider the South African R\&D data and suite of analytical products as one key source of evidence in their forecasting and scenario building.

For funders: The data presented in this paper provide a mirror of the key R\&D performance trends over a 10-year period, including those research fields that are thriving, as it were, and those that are diminishing. We recommend that funders also pay particular attention to South African R\&D data and results in funding allocation decisions.

For R\&D Survey managers: We have shown that there is room for improvement in the classification of research fields. To limit the reporting of unclassified expenditure, it is essential for the R\&D Survey managers to ensure that appropriate space and scope for reporting expenditure are provided.

\section{Acknowledgements}

We acknowledge Precious Mudavanhu from the Centre for Science, Technology and Innovation Indicators (CeSTII) of the Human Sciences Research Council (HSRC) for data and statistical support. We also acknowledge Dr Glenda Kruss and Dr Christa Van Zyl of the HSRC as well as the anonymous peer reviewers for comments on earlier drafts of this article. This article was prepared under the auspices of the CeSTII at the HSRC. CeSTII receives financial support from the Department of Science and Technology.

\section{Authors' contributions}

N.M. was responsible for the data collection; N.M. and G.R. were responsible for conceptualisation, methodology, data analysis, validation and the write-up.

\section{References}

1. Dubow S. Scientific racism in modern South Africa. Cambridge, UK: Cambridge University Press; 1995.

2. Dubow S. A commonwealth of knowledge: Science, sensibility and white South Africa 1820-2000. Oxford: Oxford University Press; 2006.

3. Shepherd N. State of the discipline: Science, culture and identity in South African archaeology, 1870-2003. J South Afr Stud. 2003;2(4):823-844. https://doi.org/10.1080/030.570.7032000135842
4. Centre for Research on Evaluation, Science and Technology (CREST). Mapping social sciences research in South Africa Part II: The political economy of social sciences research in South Africa. Stellenbosch / London: CREST / UK Department for International Development; 2014.

5. South African Department of Arts, Culture, Science and Technology (DACST). White paper on science and technology: Preparing for the 21st century. Pretoria: DACST; 1996.

6. South African Department of Science and Technology (DST). Towards the 2017 white paper on science, technology and innovation: Inclusive development through science and innovation. Pretoria: DST; 2017.

7. Academy of Science of South Africa (ASSAf). Consensus study on the state of the humanities in South Africa: Status, prospects and strategies. Pretoria: ASSAf; 2011. Available from: http://hdl.handle.net/20.500.11911/33

8. South African Department of Higher Education and Training (DHET). Report commissioned by the Minister of Higher Education \& Training for the Charter for Humanities and Social Sciences. Final report. Pretoria: DHET; 2011.

9. Mouton J. The Humanities and Social Sciences in SA: Crisis or cause for concern. S Afr J Sci. 2011;107(11/12), Art. \#961, 4 pages. http://dx.doi. org/10.4102/sajs.v107i11/12.961

10. Higher Education Act (101/1997), Republic of South Africa. Regulations for the establishment of a national institute for the humanities and social sciences. Government Gazette, 5 December 2013. Pretoria: Government Printers; 2013

11. Potgieter C, Bob U, Sooryamoorthy R. Assessing the environment for social science research in developing countries: The case of South Africa. Final report. Durban: University of KwaZulu-Natal / Global Development Network; 2016.

12. Centre for Research on Evaluation, Science and Technology (CREST). Mapping social sciences research in South Africa Part I: Mapping of research centres. Stellenbosch London: CREST / UK Department for International Development; 2014.

13. Essop A. Report on the state of the arts, humanities and social sciences in South African universities: Prepared for the Andrew W. Mellon Foundation [document on the Internet]. c2015 [cited 2018 Feb 14]. Available from: https://mellon.org/media/filer_public/c6/38/c6388113-6eb5-4f0e82ff-0639b733abc3/arts_humanities_social_sciences_south_african_ universities.pdf

14. American Academy of Arts and Sciences (AAAS). The heart of the matter. Cambridge, MA: AAAS; 2013.

15. Organisation for Economic Co-operation and Development (OECD). Frascati manual: Proposed standard practice for surveys on research and experimental development. Paris: OECD; 2002.

16. Organisation for Economic Co-operation and Development (OECD). Frascati manual: Guidelines for collecting and reporting data on research and experimental development. Paris: OECD; 2015.

17. Human Sciences Research Council (HSRC). South African national survey on research and experimental development: Statistical report 2014/15. Cape Town: Centre for Science, Technology and Innovation Indicators, HSRC; 2017. 